\title{
Reflections on the Propaganda and Ideological Work of the Communist Youth League in Colleges and Universities under the Background of "Micro Era"-Taking the Official WeChat Platform of Guangxi University of Science and Technology as an Example
}

\author{
Zhihua Jiang \\ Guangxi University of Science and Technology, Liuzhou, Guangxi Autonomous Region, China
}

Keywords: WeChat platform; the Communist Youth League; propaganda and ideological work; reflection.

\begin{abstract}
With the rapid development of new media and the Internet, the Communist Youth League is now facing new changes, opportunities and challenges in the propaganda and ideological work from perspectives of working concepts and methods, working contents and modes, as well as working environment and characteristics of the youth. In this "micro era", it is of practical significance for the Communist Youth League to use "Internet plus" thinking mode, and to actively explore new ways and innovative methods in propaganda and ideological work, which will help to enhance the cohesion, affinity and credibility of the Communist Youth League. In this paper, the WeChat account platform of the Communist Youth League of Guangxi University of Science and Technology is served as the example. Through investigation and analysis of the behavior patterns of 960 college students on WeChat using and related influences, this paper tries to explore how to create a new propaganda position for the Communist Youth League by using new media, and how to lead the new normal and ensure new achievements through network ideology.
\end{abstract}

\section{Introduction}

In the micro era, WeChat public platform has attracted the attention from most young college students; it has occupied the leading position in ideology guidance for the Communist Youth League, who needs to actively explore new educational methods through the Internet. In this paper, the Communist Youth League of Guangxi University of Science and Technology is taken as an example. The Communist Youth League of Guangxi University of Science and Technology gives full play to its guiding role in organizing, serving and safeguarding the legitimate rights and interests of young people, and actively explores new media propaganda methods. Through building the "Youth of Guangxi University of Science and Technology" WeChat public platform, the Communist Youth League explores the using of "Internet plus" thinking in propaganda work, creates a new position for the construction of campus culture, and forms the new normal of network ideological leading; it creates a "344" new media brand for the Communist Youth League.

\section{Analysis on Using Status of WeChat among College Students}

With the popularity of smart phones, today, almost every college student has at least one smart phone, which can meet their requirements on daily communication and Internet using to a large extent. The rapid development and popularization of new media represented by smart phones has brought a revolutionary change in human communication; new media transform the learning, living, working and behavioral patterns of people, especially the young students.

WeChat is one of the most representative platforms of new media. Its unique voice chat function can transfer emotion information successfully; users can post text and pictures through the Wechat Moments, as well as "comment" and "like" the posts of their friends. These functions help Wechat to gain the popularity of young people in a short period of time. Apart from these basic functions, WeChat public platform has a new functional module, which allows users to publish text, pictures, 
voice messages, video messages and messages with both texts and pictures. The public platform greatly expands the functions of WeChat and satisfies users' needs. Taking Guangxi University of Science and Technology as an example: there are nearly one hundred WeChat official accounts in the college. The use of these accounts provides a new channel in daily life and ideological education for college students, and helps them to grow up and become useful. So, in real life, how college students use WeChat? In daily life and learning, what influences do WeChat bring to college students? What kinds of challenges and conveniences do WeChat and other new media bring to the ideological and political education departments? As a leader in college Communist Youth League, it is necessary to carry out in-depth investigation and study on these issues. Thus, the author investigates 960 college students from Guangxi University of Science and Technology; through relatively survey analysis, it is found that college students have something in common in the usage of WeChat:

Basic situation of WeChat using. According to answers to the first question in the questionnaire, namely the "WeChat uses data", up to 97.32\% students express that they are using WeChat application. WeChat has become an indispensable social tool for college students. From the statistical data of the second question, "the duration of using WeChat per day", among the $97.32 \%$ WeChat users, relatively "addicted" users who use WeChat for "more than 6 hours a day" account for 18\%; people who spend 4 to 6 hours account for $27 \%$. That is to say, nearly half of students use WeChat more than 4 hours every day. Thus it can be seen, the new media is a "double-edged sword". Using the new media platform of WeChat could lead to serious consequences without students' self-control and proper guidance from the school. The fourth question is the purpose of WeChat using. $48 \%$ students hope that WeChat can meet their own social and entertainment needs; 31\% students use Wechat to satisfy their own curiosity and get to know their friends' life through Wechat Moments; only 18\% student use WeChat to study new knowledge and read a variety of "chicken soup articles". This shows that fro college students, WeChat is mainly used by as a new type of social entertainment tool, instead of learning channel.

The influences of WeChat on college students. Up to 72\% students often use WeChat with lower heads when they walking alone, sitting in classroom and lying in bed "before getting up and falling asleep". This habit can reduce the efficiency of classroom learning, break the normal work and rest routine, and even affect students' personal safety. Up to $81 \%$ college students like to use WeChat at parties and at home during holidays, which decrease the face-to-face communication between relatives and friends. WeChat provide convenience for communication over time and space, but impact the communication at our sides. $75 \%$ students choose to communicate through Wechat instead of telephone, since the voice message and video chat functions of Wechat is very convenient and greatly reduces the communication costs compared with traditional mobile phone calls and text messages; Wechat also adds emotion information, immediacy, regularity and authenticity to the communication. 63\% students believe that on Wechat platform, some of the "chicken soup" articles and "beautiful pictures and texts" help to expand their horizons. 25\% students express that a lot of negative energy, even anti party speech and more antisocial rumors spread on the network are not real; but sometimes these various information are difficult to tell, and can mislead college students who are in the critical stage of values formation. These are the negative influences of Wechat.

College students' attention to all kinds of WeChat official accounts. 78\% students follow at least 1 WeChat official account, of which 54\% students follow the official account of "Guangxi University of Science and Technology"; 48\% of them follow the "Communist Youth League of Guangxi University of Science and Technology". Other official accounts, such as accounts of student organizations and the Students' Union also attract the attention from college students. Among students who follow the official account of "Guangxi University of Science and Technology", 67\% are active followers who use the account to get to know news, information and activities; $14 \%$ are passive followers under the requirement of their teachers. Nearly $35 \%$ students who follow the account rarely read or browse relative information. 85\% students love passages which have illustrations, use "youth style" language, have eye-catching titles and deal with topics closely related to the life of college students. 33\% students believe that the content of official account is too "official and formal" and not attractive enough; the content and form need to be improved. 52\% concerns the 
cost of data flow when browsing the official account, and suggest the school to provide Wi-Fi coverage and improve the information level. From data collected, it can be analyzed that freshman followers are relatively active; they form the main group of liking, forwarding and comments interaction.

\section{Building "Three Layers" New Media Group Structure for League Leaders, Constructing All-media Propaganda Matrix}

The Communist Youth League of Guangxi University of Science and Technology (GXUST) adheres to the mutual development of "traditional media and new media", as well as the combination of "multi-dimensional coverage and focus on key points", and forms a new media group with three layers, in which "double micro and one website" (i.e.: micro blog, WeChat and the website of the Communist Youth League of GXUST) serve as the core layer, micro blog and WeChat of Communist Youth League of school faculties serve as the fixed layer, while WeChat official accounts established by student associations and other influential student organizations serve as the external layer. The new media group is now an important pillar of league and student work. It helps the Communist Youth League of GXUST to promote the development of new media group, hold the leading position of public opinion, enhance personnel's capacities on assessment and incentive about new media, and organize activities like business training and learning with students.

\subsection{Improving organizational structure, and establishing a "new media center for the youth"}

New media center for the youth is a new media practice organization which serves young college students school and directly under the leadership of the Communist Youth League of Guangxi University of Science and Technology. The center consists of six departments: editorial department, secretary department, operation department, design department, technical department and youth group. It has following responsibilities: daily maintenance and content editing of the official WeChat account, the micro-blog and other platforms of the Communist Youth League of GXUST; learning and guiding the trend of public opinion in school; planning and operating online and offline activities; designing pages of the website; regularly posting news about youth to new media; applying and developing platform; taking videos and pictures. More than 50 staffs work for the center to adapt to the growing popularity of new media among young college students. The center help students to improve their abilities on new media using, and promote league organizations at all levels to focus on new media in educating and guiding the youth.

\subsection{Setting "three menus, eight youth topics" and using new media to serve the youth.}

The new media group of youth operates the WeChat official account of school league. The account has three menus include "Youth Science", "Youth Innovation" and "Campus Service". Articles on eight "youth" topics are posted regularly or irregularly, including Youth Thinking (Monday), Youth Interview (Tuesday), Youth Reading (Wednesday), Youth Action (Thursday), Youth Topics (Friday), Youth Original Works (Saturday) and Youth Trends (Sunday). The content of these articles "focuses on youth, serves the youth, stays close to the youth and influences the youth". In addition to the eight youth topics, the account also provides a number of service functions, including school calendar, educational administration office, information navigation, query results, bus query, lecture information, campus activities and so on, in order to attract the attention of students. The platform now has more than 30000 followers, and has become the most influential new media platform in school.

\subsection{Achieving "full coverage" and building big propaganda matrix.}

Group organization of each schools and departments set up accounts of micro blog and Wechat; Students' Union and other influential student organizations also create WeChat accounts to achieve the full coverage of new media on all members of the Communist Youth League, and to construct the new media propaganda matrix. Through the new media platform, these organizations can timely release information about employment, campus cultural activities, community activities and so on. 
These accounts focus on academic research, interest cultivation, professional learning, employment and volunteer services. Their contents combine knowledge, beautiful photos and entertainment information together. These accounts also make full use of school seasons, graduation, important festivals and other important themes to carry out online and offline activities, in order to enhance participation and increase the number of followers. The influences and popularity of the new media platform grow with each passing day. College students, alumni and other people actively follow the WeChat account and take part in interaction.

\section{Creating "Four Big" Education Projects, and Using Network Thinking to Lead the New Normal}

\subsection{Follow the examples of good youth: outstanding young people project.}

The first session of the "Most Beautiful GXUST" Person of the Year was held successfully. The activity was launched by WeChat platform and publicized by the network. In the link of network voting, 26 candidates won more than 340 thousand number of "like". Relevant pages were put on the school website; the click rate was more than 1000 times per day. In the end, 10 college students won the title of the year. The activity enjoyed warm responses and widespread concern among young people in school. Through the WeChat platform, online and offline publicity activities are carried out to guide young people to learn from the excellent youth around them. Under the background of new normal, it is one of the brand activities which cultivate and practice the core socialist values.

\subsection{Reading and promoting good books: reading and writing micro book review project.}

The league uses WeChat platform to carry out "Youth Reading, Micro Book Review" activities every Wednesday in the "Youth Reading" section. Through the promotion of modern network technology, good books and book reviews can be introduced to college students. "Micro Book Reviews" expresses readers' feelings after reading, which can be seen as the concise comments on the content of the books. This project can promote the exchanges of good books among college students, stimulate the reading enthusiasm of college students, and help to form a reading trend in campus.

\subsection{Learning Lei Feng and building up new spirit: volunteer service project.}

The development of new media platform make learning "Lei Feng Spirit" and publicizing "Lei Feng" story more diverse and direct. The league can carry out public contests on volunteer ideas on the basis of WeChat platform; launch the activity of "Shooting and Maker" to make public welfare activities more creative and warmhearted; carry out "Clean Your Plate" and "Save Every Bit of Electricity" actions activities online and offline; launch theme activities like "Searching for Lei Feng Beside Me", "Passing on the Spirit of Lei Feng", "Lei Feng Spirit and the Core Socialist Values", "Micro News, Micro Public Welfare", "Writing the Diary of Lei Feng" on the WeChat platform; organize the activity of "Vote for the Most Beautiful Lei Feng in Your Eyes". League organizations at all levels can show their "Lei Feng" activities through the WeChat platform. Participants can express their experience and gains through voluntary services, and get votes from their friends. Under the influence of these activities, everyone in campus helps the others and tries to become Lei Feng.

\subsection{Living associations and promoting school culture: campus culture promotion project.}

To carry out student community cultural festival, various student organizations need to display themselves through online publicity. "Ten Top Communities" and "Best Communities" are selected through the network to actively create community network culture. Online vote about "My Favorite Campus Cultural Activities" gives students the right to decide how to run campus cultural activities. Activities like "Culture and Art", "Science and Technology Festival" are launched through brainstorm. "High Art in Campus", "Celebrities in the Campus" and other activities which need students to compete the tickets should be held regularly. Students can get the ticket through following the WeChat account and forward related articles. In this way, students can truly become participants and beneficiaries of the prosperous campus culture. 


\section{Creating "Four" Actions to Ensure Network Thinking Leads New Results}

5.1 Taking multiple, mutual promoted actions: combining online and off-line activities to attract followers, increasing interactions and enhancing the influence of WeChat platform.

The Youth League WeChat platform and other new media have the most active audience groups: young college students. The Communist Youth League in colleges and universities should use activities as the carrier, and enhance its influence and transmission power through online and offline linkage and new media interaction. Through activities, the "three layers" of new media groups can integrate into a compact organic whole. The new media of the whole school should be linked together; scattered information which released in each WeChat platform should be gradually integrated. In the overall promotion and implementation of important activities, key themes activities and large scale plans, new media platforms can work with each other to promote and maximize the publicity effect.

5.2 Adopting "external publicity" measures: strengthening external publicity, enhancing the internal and external attractive force of WeChat platform, building school image and spreading positive energy.

The integration of new media resources focuses on propaganda and guidance. New media plays their roles in promoting positive energy, shaping the image of the school, optimizing mechanism, further enhancing the "internal" and "external" capacities, and giving full play to the dissemination power of new media. Through the publicity and planning of theme activities like the "Most Beautiful GXUST" Person of the Year, "My Favorite Students Association Competition" and "My Favorite Campus Cultural Activities" vote, "Show Campus Songs by Myself" and "Shot Graduation Photos by Myself", new media resources are integrated; positive energy and new fashion spread in school. The first session of "Most Beautiful GXUST" Person of the Year award got 340 thousand votes; the GXUST version of "A Little Happiness" was clicked for over 10000 times. The two activities serve as good examples.

5.3 "Content production" actions: adhering to principles of "content oriented" and "diverse forms"; getting development advantages through content and form which can attract college students and enhancing the effectiveness of thematic education.

General Secretary Jin-ping Xi puts forward the principle that we need to use "advanced technology as the support and content construction as the foundation". The core competitiveness of media is the content, especially original content. In the current network, WeChat and micro-blog disseminate both right and wrong information, which makes readers difficult to tell. Under that situation, original content is the key for new media to achieve sustainable and healthy development. The WeChat platform of the Communist Youth League should adhere to the content oriented and technology support principle, strengthen content editing, innovate work forms and develop original works which combine thinking, education, communication and entertainment together, trying to change the old school "preaching" to new style content with vivid language and various forms. Through the attractive contents, the attractiveness and effectiveness of WeChat platform can be enhanced.

\section{4 "Guarantee mechanism": establishing and improving the management operation} mechanism of new media to ensure the healthy and sustainable development of new media platform.

Establishing guarantee mechanism include following steps. First, training and testing should be strengthened to enhance the ability and quality of new media personnel which serve young college students. The political literacy and network abilities of related personnel must be improved to make sure that they would not make mistakes on major issues. Second, supervision mechanism should be established. For rational proposals and demands put forward by net friends, "every case should be responded". Third, investment guarantee mechanism should be established to provide policy support, human resource, funds, hardware, public opinion monitoring and response, as well as other aspects of mechanisms for the new media platform. Fourth, the network literacy education of college students 
needs to be strengthened. A series of notices and documents, such as Network Civilization Convention and Behavioral Rules for College Students should be issued to effectively regulate behaviors on the Internet, so as to ensure the healthy and sustainable development of new media platform.

\section{Acknowledgement}

Project Foundation: This paper is one of the outcomes of the research, Research on Reform and Innovation of the Communist Youth League's Propaganda and Ideological Work Modes under the Background of "Internet Plus", which is supported by the Foundation for Key Theoretical and Practical Research Projects on Students' Ideological and Political Education in Colleges and universities of Guangxi in 2015 (Project No:. 2015MSZ018); it is also one of the fruits of the research, Research on the Construction of Compatible Propaganda Structure among Colleges under the Background of "Internet Plus" and Mode Innovation, which is supported by the Foundation for Projects on the Enhancement of Young College Teachers' Basic Capacities in 2016 (Project No:. KY2016LX151). It is also one of the research outcomes of the Project on Development of Humanities and Social Science Programs in Guangxi University of Science and Technology in 2017.

\section{References}

[1] Y. Zhang, Opening up new field on leading ideology for the Communist Youth League through new media, J. Statistics and Management. 3 (2016).

[2] W.B. Qian, The impact of new media on college students' value orientation and countermeasures, J. Press Circles. 3 (2010).

[3] S.B. Yu, Coping strategies of ideological and political education under the background of new media, J. The Party Building and Ideological Education in Schools. 23 (2010). 